\title{
In a novel form of IFN- $\gamma$ receptor 1 deficiency, cell surface receptors fail to bind IFN- $\gamma$
}

\author{
Emmanuelle Jouanguy, ${ }^{1,2}$ Stéphanie Dupuis, ${ }^{1,2}$ Annaïck Pallier, ${ }^{2}$ Rainer Döffinger, ${ }^{1,2}$ \\ Marie-Claude Fondanèche, ${ }^{2}$ Claire Fieschi, ${ }^{1,2}$ Salma Lamhamedi-Cherradi, ${ }^{2}$ \\ Frédéric Altare, ${ }^{1,2}$ Jean-François Emile, ${ }^{3}$ Patrick Lutz, ${ }^{4}$ Pierre Bordigoni, ${ }^{5}$ \\ Haluk Cokugras, ${ }^{6}$ Necla Akcakaya, ${ }^{6}$ Judith Landman-Parker, ${ }^{7}$ Jean Donnadieu, ${ }^{7}$ \\ Yildiz Camcioglu, ${ }^{6}$ and Jean-Laurent Casanova ${ }^{1,2,8}$
}

\author{
${ }^{1}$ Laboratoire de Génétique Humaine des Maladies Infectieuses, Faculté de Médecine Necker, Paris, France, EU \\ ${ }^{2}$ Institut National de la Santé et de la Recherche Médicale Unité 429, Hôpital Necker-Enfants Malades, Paris, France, EU \\ ${ }^{3}$ Service d'Anatomie Pathologique, Hôpital Paul Brousse, Villejuif, France, EU \\ ${ }^{4}$ Unité d’Hématologie-Oncologie, Service de Pédiatrie 1, Hôpital de Hautepierre, Strasbourg, France, EU \\ ${ }^{5}$ Service d'Hématologie Pédiatrique, Hôpital d'Enfants de Nancy, Vandoeuvre, France, EU \\ ${ }^{6}$ Infeksiyon Hastaliklari Klinik Immunoloji ve Allerji Bilim Dali, T.C. Istanbul Üniversitesi, Cerrahpasa Tip Fakültesi, \\ Istanbul, Turkey \\ ${ }^{7}$ Service d'Hématologie Pédiatrique, Hôpital Trousseau, Paris, France, EU \\ ${ }^{8}$ Unité d'Immunologie et d'Hématologie Pédiatriques, Hôpital Necker-Enfants Malades, Paris, France, EU
}

Address correspondence to: Jean-Laurent Casanova, Laboratoire de Génétique Humaine des Maladies Infectieuses,

Faculté de Médecine Necker, 156 rue de Vaugirard, 75015 Paris, France, EU.

Phone: 33-1-40-61-53-81; Fax: 33-1-42-73-28-96; E-mail: casanova@necker.fr.

Received for publication December 15, 1999, and accepted in revised form April 6, 2000.

\begin{abstract}
Complete IFN- $\gamma$ receptor ligand-binding chain (IFN $\gamma \mathrm{R} 1$ ) deficiency is a life-threatening autosomal recessive immune disorder. Affected children invariably die of mycobacterial infection, unless bone marrow transplantation is undertaken. Pathogenic IFNGR1 mutations identified to date include nonsense and splice mutations and frameshift deletions and insertions. All result in a premature stop codon upstream from the segment encoding the transmembrane domain, precluding cell surface expression of the receptors. We report herein two sporadic and two familial cases of a novel form of complete IFN $\gamma \mathrm{R} 1$ deficiency in which normal numbers of receptors are detected at the cell surface. Two in-frame deletions and two missense IFNGR1 mutations were identified in the segment encoding the extracellular ligand-binding domain of the receptor. Eight independent IFN $\gamma \mathrm{R} 1$-specific $\mathrm{mAb}$ 's, including seven blocking antibodies, gave recognition patterns that differed between patients, suggesting that different epitopes were altered by the mutations. No specific binding of ${ }^{125}$ I-IFN- $\gamma$ to cells was observed in any patient, however, and the cells failed to respond to IFN- $\gamma$. The mutations therefore cause complete IFN $\gamma \mathrm{R} 1$ deficiency by disrupting the IFN- $\gamma$-binding site without affecting surface expression. The detection of surface IFN $\gamma \mathrm{R} 1$ molecules by specific antibodies, including blocking antibodies, does not exclude a diagnosis of complete IFN $\gamma \mathrm{R} 1$ deficiency.
\end{abstract}

J. Clin. Invest. 105:1429-1436 (2000).

\section{Introduction}

Complete IFN- $\gamma$ receptor ligand-binding chain (IFN $\gamma \mathrm{R} 1)$ deficiency is a rare, life-threatening, autosomal recessive human immune deficiency (MIM107470) $(1,2)$. Affected children invariably develop disseminated bacille Calmette-Guérin (BCG) infection shortly after inoculation with live BCG vaccine (3-6). Rare survivors and nonvaccinated children develop severe infections caused by environmental non-tuberculous mycobacteria (NTM) in early childhood (4-8). Other clinical infectious diseases have been reported, but they are much less frequent and severe $(9,10)$. The pathogens identified include intracellular bacteria, such as Salmonella (7) and Listeria (6), and viruses, such as varicella-zoster virus $(6,10)$ and cytomegalovirus $(5$, 10). Mycobacterial granulomas are often multibacillary and in all cases are poorly delimited (no surrounding lymphocytes) and differentiated (no epithelioid or giant multinucleated phagocytic cells) (2). Affected children generally die in childhood because antibiotics do not give sustained remission of mycobacterial disease and IFN- $\gamma$ therapy is ineffective in the absence of specific receptors (2). Bone marrow transplantation is the only curative treatment available $(2,6)$.

A variety of IFNGR1 null recessive mutations are associated with complete IFN $\gamma$ R1 deficiency (2). They include nonsense $(7)$ and splice $(5,6,11)$ mutations and frameshift insertions (11) and deletions $(3,5,6)$. The mutations affect different nucleotides in the IFNGR1 coding region, and neither founder nor recurrent mutations have been identified. However, all the reported mutations share two features. First, they are 
located in the segment encoding the extracellular domain of the receptor. Second, they result in a premature stop codon upstream from the region encoding the transmembrane domain, thereby precluding expression of the receptors at the cell surface. No IFN $\gamma \mathrm{R} 1$ molecules are detected at the cell surface by flow cytometry with specific mAb's (2). The cells of patients have been shown not to respond to IFN- $\gamma$ in experiments with freshly prepared PBMCs $(5,7,12)$, Epstein-Barr virus-transformed (EBV-transformed) Bcell lines (13), and SV40-transformed fibroblast cell lines (11). Molecular complementation of the cellular defect by transfection with the wild-type IFNGR1 gene has demonstrated a causal relationship between the IFNGR1 mutations and the cellular phenotype (11). We report herein four patients from three unrelated families with a novel form of complete IFN $\gamma R 1$ deficiency in which IFN $\gamma \mathrm{R} 1$ molecules are expressed at the cell surface but do not bind IFN- $\gamma$.

\section{Methods}

Patients. Four patients from three unrelated families were investigated. Clinical features will be reported elsewhere. Briefly, all presented with disseminated BCG infection shortly after inoculation with live BCG vaccine. Biopsies were taken and multibacillary, poorly delimited, and poorly differentiated tissue granulomas were found in all patients (type II; ref. 14). No other unusual infections were observed. Immunological investigation detected no classical immunodeficiency conditions that might predispose patients to BCG infection $(15,16)$. Patient I.1 was the only child born to first-cousin parents from Algeria living in France. She was vaccinated at 1 year of age, and BCG infection was successfully treated with antimycobacterial drugs for 1 year. Three months after the antibiotics were discontinued, disseminated Mycobacterium avium infection was diagnosed. Partial remission was obtained with antibiotics. The child underwent bone marrow transplantation from an HLA-identical uncle at 3 years of age and died 2 months later from a disseminated granulomatous reaction after full engraftment. Patients II.1 and II.2 were born to consanguineous Turkish parents living in Turkey. The girl (II.1) had recurrent BCG infection that responded poorly to antibiotic treatment. At 10 years of age disseminated Mycobacterium fortuitum was diagnosed. She is now 11 years old and very ill despite antibiotic treatment. The boy (II.2) had recurrent BCG infection until 8 years of age, when disseminated Mycobacterium fortuitum infection was also diagnosed. He is now 9 years old and is in partial remission with multiple antibiotic treatment. Two siblings died at 3 years of age of acute leukemia and typhoid fever. Three others, now aged 18,21, and 25, have been vaccinated with BCG with no adverse effect and are healthy. Patient III.1 was the second child born to a French mother and a Portuguese father living in France. Disseminated BCG infection was diagnosed at an early stage and respond- ed well to antimycobacterial drugs that have been continued. She is now 2 years of age and is currently undergoing transplantation with HLA-haploidentical bone marrow from her mother. Her older brother was vaccinated with BCG with no adverse effects and is doing well at 5 years of age.

Molecular genetics. Genomic DNA was extracted from blood cells and EBV-transformed B cells (EBV-B cells), and the IFNGR1 exons and flanking intron regions were amplified as described elsewhere $(11,17)$. Exons 2, 3 , and 5 were amplified using the following primers: exon 2, sense 5'-ATC TTA CAA TAA ggC TTT CC-3' and antisense $5^{\prime}$-AAg gAC CTA AAC AAA AAT gg-3'; exon 3: sense $5^{\prime}$-CTg TgA ATA AAA AgC AAA gC-3' and antisense $5^{\prime}$-AAA gCA AAC ATA CAg AAg AC-3'; exon 5, sense $5^{\prime}-\mathrm{TgA}$ CCA ggA CTA ATA Tgg Tg- $3^{\prime}$ and antisense 5'-ACT gCT CCC TCT ATA TTT Ag-3'. PCR cycling conditions were as follows: 5 minutes at $94^{\circ} \mathrm{C}$ followed by 35 amplification cycles $\left(1\right.$ minute at $94^{\circ} \mathrm{C}$, 1 minute at $50-56^{\circ} \mathrm{C}, 1$ minute at $72^{\circ} \mathrm{C}$ ) and $10 \mathrm{~min}$ utes at $72^{\circ} \mathrm{C}$. RNA extraction, cDNA synthesis, and IFNGR1 cDNA-PCR were performed as described previously (17). PCR products were directly sequenced as described previously (17).

IFN $\gamma R 1$ detection with antibodies and IFN- $\gamma$. PBMCs were isolated as described previously (13). PBMCs or EBV-B cells were stained with mouse mAb's specific for human IFN $\gamma R$ 1 or their isotypic control antibodies. They were then incubated with biotinylated rat anti-mouse antibody (Immunotech, Marseilles, France) and streptavidin-phycoerythrin (Tebu, Le Perray en Yvelines, France). Antibody GIR94 is IgG2b (Genzyme Pharmaceuticals, Cambridge, Massachusetts, USA) (18) and other specific antibodies are IgG1 and include 21/31.1 (Valbiotech, Paris, France), GIR208 (Genzyme) (18), $\gamma$ R38 and $\gamma$ R99 (19), A6 (20), 177.1 (21), and IR $\gamma 2$ (22). All antibodies were independent, and all but one (GIR94) were blocking antibodies. EVB-B cells and gated monocytes were analyzed on a FACScan flow cytometer using Lysis-II or Cellquest software (Becton Dickinson Immunocytometry Systems, San Jose, California, USA). Specific binding of nonglycosylated ${ }^{125}$ I-IFN- $\gamma$ to EBV-B cell surface IFN $\gamma R 1$ molecules was quantified after 1 hour incubation at $4^{\circ} \mathrm{C}$ as described previously $(17,23)$.

Early and late cellular responses to IFN- $\gamma$. EBV-B cells were cultured, activated by incubation for 30 minutes with various concentrations of recombinant nonglycosylated human IFN- $\gamma$ (BioGenex Laboratories, San Ramon, California, USA), and lysed on ice as described previously $(13,24)$. The mobility shift assay was performed using nuclear extracts (10 $\mu$ g protein) and a ${ }^{32} \mathrm{P}$-endlabeled double-stranded DNA probe corresponding to the IFN- $\gamma$ response region (gamma activating sequence [GAS]). SV-40-transformed fibroblasts were cultured and stimulated with IFN- $\gamma$ for 48 hours as previously reported (11). Cell surface HLA-DR molecules were detected by flow cytometry using specific antibodies as described previously (11). 
Table 1

Mutations in the IFNGR1 gene-coding region

\begin{tabular}{lllll}
\cline { 2 - 3 } & Mutation $^{\text {A }}$ & Full-length protein & Mature protein & Affected domain $^{\text {B }}$ \\
I.1 & 295 del12 & deletion of Trp-Val-Arg-Val 99-102 & deletion ofTrp-Val-Arg-Val 85-88 & I \\
II.1/2 & C77Y & substitution of Cys 77 & substitution of Cys 63 & I \\
III.1 & V61Q & substitution of Val 61 & substitution of Val 47 & I \\
& 652del3 & deletion of Glu 218 & deletion of Glu204 & II
\end{tabular}

ANomenclature for mutations follows reference 27. Patients I.1, II.1, and II.2 are homozygous for their respective IFNGR1 mutations. Patient III.1 is a compound heterozygote. ${ }^{B}$ Effect of the mutation on the full-length, encoded protein (25). ${ }^{C}$ Effect of the mutation on the mature, cell surface protein after cleavage of the signal peptide according to ref. 28 . Note that the signal peptide is three amino acids longer according to references 25 and 41 . ${ }^{D}$ Domain I of IFN $\gamma R 1$ encompasses amino acids 17-105 and domain II, residues 117-224.

\section{Results}

We studied four children with unexplained mycobacterial infection. Two cases were sporadic (I.1 and III.1) and two were familial (II.1 and II.2, siblings). The three families were unrelated (I, Algeria; II, Turkey; III, France/Portugal). Given the severe clinical (early onset, overwhelming BCG and NTM infections) and histological (lepromatous-like granulomas) phenotype, mutations in IFNGR1 were sought $(25,26)$. Genomic DNA was extracted from blood cells and IFNGR1 exons and flanking intron regions were amplified and sequenced.

Patient I.1 was homozygous for a small in-frame deletion encompassing nucleotides 295-306 (Tgg gTC AgA gTT), designated 295del12 (Table 1, Figure 1) (27), resulting in the deletion of amino acids 99-102 (TrpVal-Arg-Val) of the protein (25). Patients II.1 and II.2 were homozygous for a missense mutation at nucleotide position 230 ( $\mathrm{TgC} \rightarrow$ T $\underline{A} \mathrm{C}$ ) designated $\mathrm{C} 77 \mathrm{Y}$ (Cys $\rightarrow$ Tyr at amino acid position 77). Patient III.1 was compound heterozygous for a missense mutation at nucleotide position $182(\mathrm{gTA} \rightarrow \mathrm{g} \underline{\mathrm{A} A})$, designated V61Q (Val $\rightarrow$ Gln at amino acid position 61 ), and for a small in-frame deletion encompassing nucleotides 652-654 (gAA) or 653-655 (AAg), both of which delete one amino acid (Glu) at position 218, designated
652 del3. The positions of the amino acid changes in the mature protein after cleavage of the 14-amino acid signal peptide are indicated in Table 1 . None of these mutations were found in 50 unrelated healthy individuals analyzed, suggesting that they are not irrelevant polymorphisms but pathogenic variants. The parents were found to be heterozygous carriers of the respective mutations, and none of the healthy siblings were homozygous or compound heterozygous for these mutations, implying that they are recessive.

Surface expression of IFN $\gamma \mathrm{R} 1$ on the cells of patients was investigated by flow cytometry with eight independent human IFN $\gamma$ R1-specific mouse mAb's (GIR94, GIR208, 21/31.1, $\gamma \mathrm{R} 38, \gamma \mathrm{R} 99, \mathrm{A6}, 177.1$, and IR $\gamma 2)$. All antibodies detected IFN $\gamma$ R 1 on the surface of EBV-B cells from a control healthy individual, but not on cells from a previously reported patient with complete IFN $\gamma \mathrm{R} 1$ deficiency caused by a homozygous IFNGR1 frameshift small deletion (131delC) (3) (Figure 2a). The eight antibodies detected normal levels of IFN $\gamma \mathrm{R} 1$ on the surface of EBV-B cells from patient I.1 (Figure 2a). In contrast, only one antibody (177.1) stained cells from the other three patients studied (not shown). As the staining of IFN $\gamma \mathrm{R} 1$ on EBV-B cells is generally weak, freshly prepared monocytes from patients II.1,

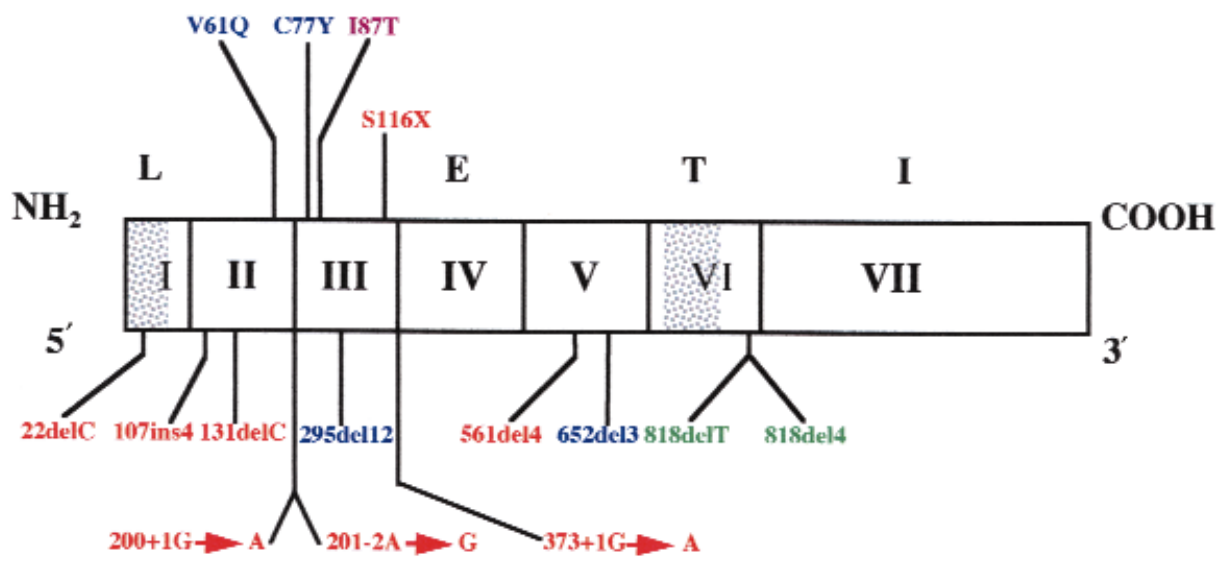

Figure 1

A novel type of mutation in the IFNGR1 gene. The IFNGR1 gene-coding region is indicated with vertical bars separating the exons, designated by roman numerals. Mutations in red (nonsense and splice mutations and frameshift insertions and deletions; recessive) have been reported elsewhere and cause complete IFN $\gamma$ R1 deficiency with no detectable expression of IFN $\gamma$ R1 at the cell surface. Mutations in purple (I87T, recessive) and green (818delT and 818del4, dominant) have also been reported elsewhere and cause partial, as opposed to complete, IFN $\gamma R 1$ deficiency. Mutations in blue (missense mutations and in-frame deletions; recessive) are reported in this study and cause complete IFN $\gamma$ R1 deficiency with detectable surface expression of IFN $\gamma$ R1. 
II.2, and III.1 were stained with the eight specific antibodies. Two antibodies (GIR94 and $\gamma$ R38) did not stain cells from patients II.1 (Figure 2b) and II.2 (not shown). The specific fluorescence obtained with the other six antibodies was normal ( $\gamma \mathrm{R} 99, \mathrm{~A} 6$, and 177.1) or weak (21/31.1, GIR208, and IR 2 ) (Figure 2b; not shown). Three antibodies (GIR94, $\gamma \mathrm{R} 38, \gamma \mathrm{R} 99)$ did not stain monocytes from patient III.1, unlike the other five antibodies (not shown). Thus, the surface expression and overall conformation of the IFN $\gamma \mathrm{R} 1$ receptors encoded by the mutant IFNGR1 alleles identified in the four patients under study were not abnormal. However, the mutations seemed to have altered various epitopes recognized by the mAb's.

We investigated the affinity of these surface-expressed mutant IFN $\gamma$ R 1 molecules for human IFN- $\gamma$. EBV-B cells from three patients (I.1, II.1, III.1), a healthy control, and a patient with no IFN $\gamma \mathrm{R} 1$ expression (3), were incubated with nonglycosylated ${ }^{125}$ I-IFN- $\gamma$. These cell lines do not secrete detectable amounts of IFN- $\gamma$ when analysed using ELISA (not shown). No specific binding of recombinant IFN- $\gamma$ was observed with cells from patients I.1, II.1, III.1, or a patient with no IFN $\gamma \mathrm{R} 1$ expression (Figure 3). In contrast, cells from a healthy control expressed receptors with a high affinity for IFN- $\gamma$. Thus, the patients' cells do not bind IFN- $\gamma$, presumably because membrane-bound IFN $\gamma \mathrm{R} 1$ molecules are mutated. The binding of glycosylated IFN- $\gamma$ was not determined, but it is expected to reflect that of the nonglycosylated form (28). The mutant cell surface receptors encoded by the 295 del12 (patient I.1) and C77Y (patients II.1 and II.2) alleles seem to have completely lost their capacity to bind IFN- $\gamma$. Because two mutant IFNGR1 alleles (V61Q and 652del3) were identified in patient III.1, it is unclear whether only one or both mutant receptors are expressed at the surface and therefore whether only one or both cannot bind IFN- $\gamma$.

We investigated whether the patients had IFNyR1 deficiency and, if so, whether it was complete or partial,

a
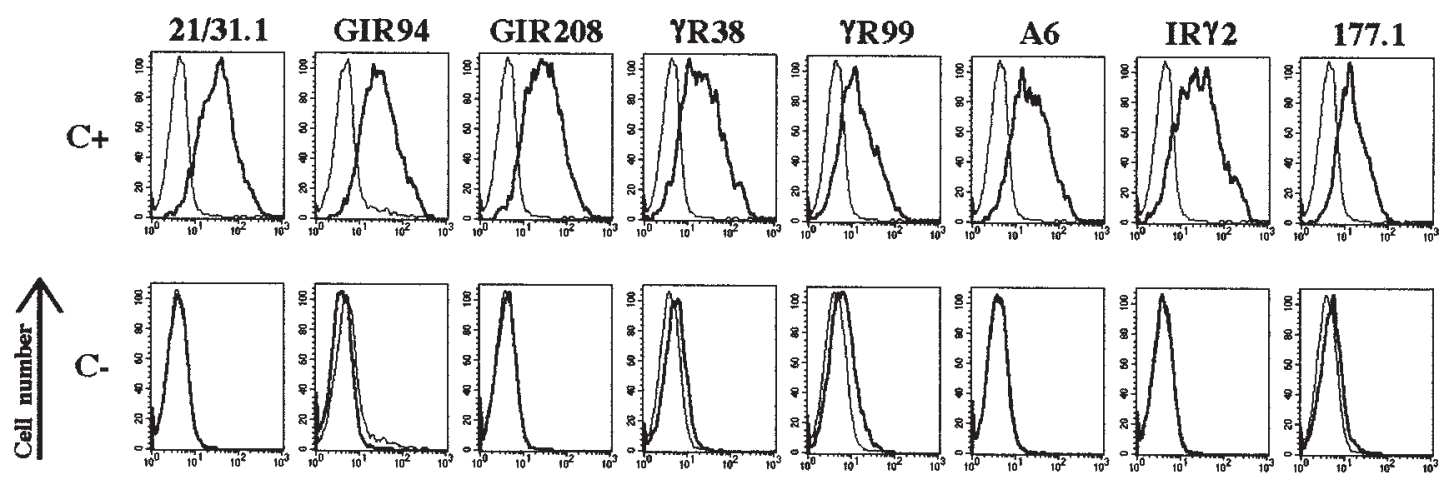

I.1
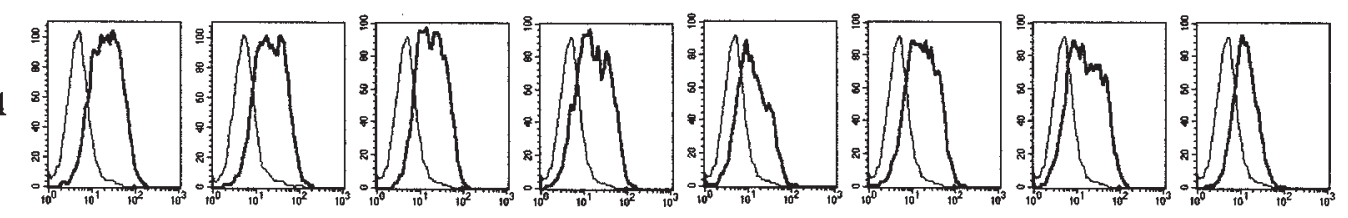

b

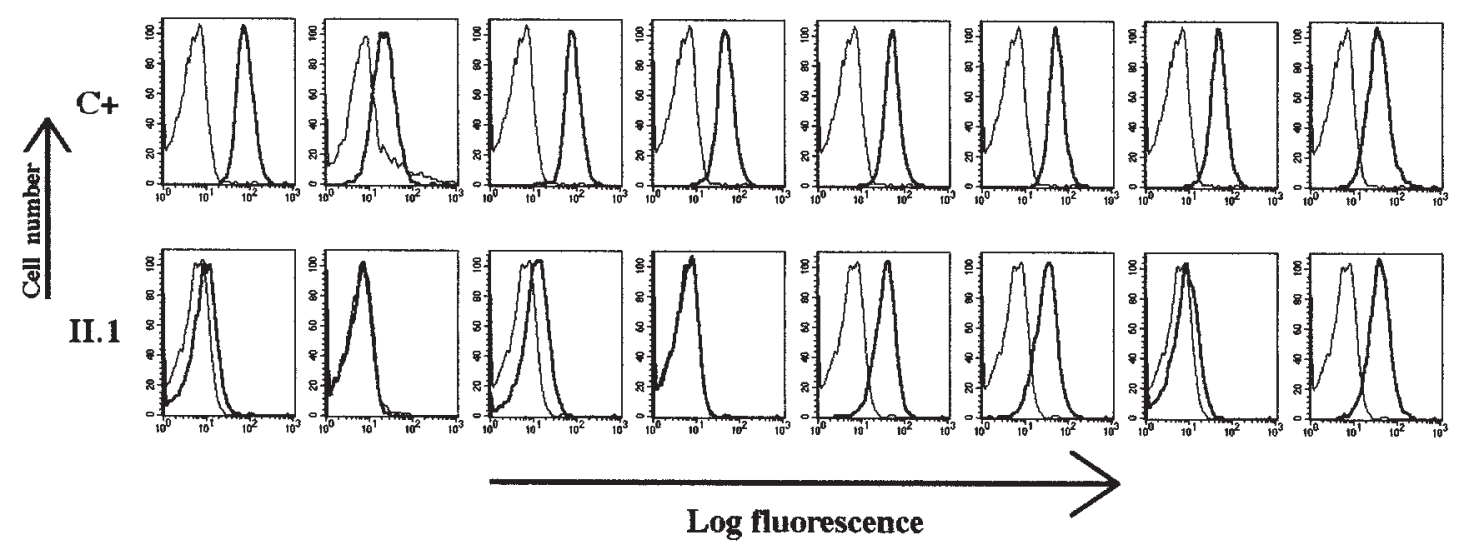

Figure 2

Detectable IFN $\gamma R 1$ molecules on the surface of the cells of the patients. (a) Cultured EBV-B cells from patient I.1, a healthy control individ-

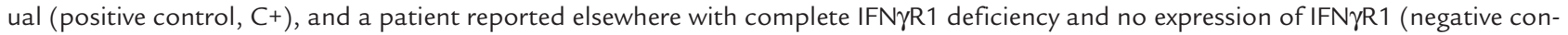

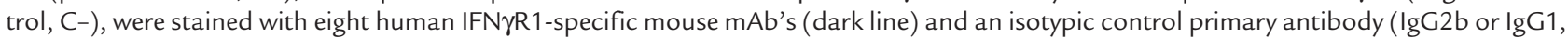
see Methods) (light line). (b) Freshly prepared monocytes from patient II.1 and a healthy control individual (positive control, C+), were stained with eight human IFN $\gamma R$ 1-specific mouse mAb's (dark line) and an isotypic control primary antibody (light line). 
by studying cellular responses to IFN- $\gamma$. EBV-B cells from three patients (I.1, II.1, III.1), a healthy individual, a patient with complete IFN $\gamma$ R1 deficiency and no IFN $\gamma \mathrm{R} 1$ expression (3), and a patient with partial dominant IFN $\gamma \mathrm{R} 1$ deficiency (17) were stimulated with IFN$\gamma$, and nuclear translocation of STAT- 1 was detected by electrophoretic mobility-shift assay. No GAS motifbinding proteins were detected in the cells of the three patients, even if these cells were incubated with high concentrations of IFN- $\gamma\left(10^{5} \mathrm{IU} / \mathrm{mL}\right)$ for 30 minutes before the preparation of a nuclear extract and its electrophoresis $(10 \mu \mathrm{g})$ (Figure $4 \mathrm{a})$. In the same experiment, no STAT- 1 was detected in cell nuclei from a patient with no IFN $\gamma$ R 1 expression and complete IFN $\gamma$ R1 deficiency. In contrast, STAT-1 molecules were detected in nuclei from a healthy control, and, at a lower level, in a patient with partial dominant IFN $\gamma R 1$ deficiency.

We then investigated a more distal event, the induction of HLA-DR molecules on the surface of SV40-transformed fibroblasts after 48 hours of stimulation with IFN- $\gamma$. No HLA-DR molecules were detected by flow cytometry using specific antibodies, if cells from patient III.1 or another patient with no IFN $\gamma$ R1 expression and complete IFN $\gamma \mathrm{R} 1$ deficiency (mutations 107ins 4 and 200+1 G $\rightarrow$ A) (11) were stimulated with high concentrations of IFN- $\gamma\left(5 \times 10^{4} \mathrm{IU} / \mathrm{mL}\right)($ Figure $4 \mathrm{~b})$. In contrast, HLA-DR molecules were detected on control fibroblasts following exposure to low (not shown) and high (Figure 4b) concentrations of IFN- $\gamma$. Fibroblasts from patients I.1, II.1, and II.2 were not available. Even though one cannot strictly exclude the possibility that an IFN- $\boldsymbol{\gamma}$-triggered signal may be detected in other experimental conditions, these results strongly suggest that the patients under study have complete IFN $\gamma$ R1 deficiency. Surface expression of IFNYR1 molecules is normal, but the capacity to bind IFN- $\gamma$ at high affinity is completely lost, accounting for the lack of detectable cellular response to IFN- $\gamma$.

\section{Discussion}

Previously reported mutant IFNGR1 alleles associated with complete IFN $\gamma R$ 1 deficiency (nonsense and splice mutations and frameshift deletions and insertions) give a premature stop codon upstream from the segment encoding the transmembrane domain, thereby precluding surface expression of the receptor (Figure 1) $(3,5-7,11)$. As a result, the cells do not respond, even to high concentrations of IFN- $\gamma$. We report herein four patients from three unrelated kindreds with a novel form of complete IFN $\gamma$ R 1 deficiency in which mutant IFNGR1 alleles encode cell surface receptors that do not bind IFN- $\gamma$ (Figure 5). Four alleles were found with either small in-frame deletions (deletions 295del12 and 652del3) or missense mutations (V61Q and $\mathrm{C} 77 \mathrm{Y}$ ) in the segment encoding the extracellular, ligand-binding region (Figure 1). Mutations 295 del12 and C77Y (homozygous) and 652del3 and/or V61Q (compound heterozygous) did not affect overall tertiary structure and transport to the cell surface, but did

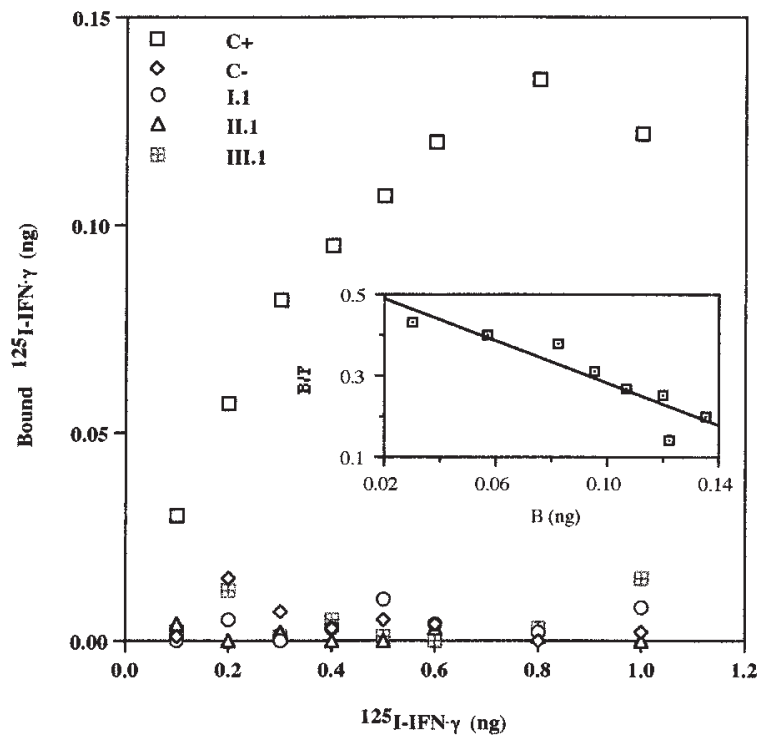

Figure 3

Lack of specific binding of ${ }^{125}$ I-IFN- $\gamma$ to the cells of the patients. Cultured EBV-B cells from the patients studied (I.1, II.1, III.1), a healthy control individual (positive control, $\mathrm{C}+$ ), and a patient reported elsewhere with complete IFN $\gamma R$ 1 deficiency and no expression of IFN $\gamma$ R 1 (negative control, $\mathrm{C}-$ ) were incubated with various concentrations of ${ }^{125}$ I-IFN- $\gamma$, and specific binding was quantified. Scatchard analysis gave $K_{a}$ values of $9.6 \times 10^{9} \mathrm{M}^{-1}$ and 602 binding sites per control cell ( $B$, bound; $F$, free). No specific binding was detected with the cells from any patient. This experiment is representative of three experiments.

prevent recognition of the encoded cell surface receptors by their natural ligand, IFN- $\gamma$. Cells from the patients therefore did not respond, even to high concentrations of IFN- $\gamma$, as shown by analysis of both early (nuclear translocation of STAT-1) and late (surface induction of HLA-DR) activation events.

This novel form of IFN $\gamma R$ 1 deficiency also contrasts with partial recessive (13) and partial dominant IFN $\gamma$ R1 deficiency (17), in which the function of detectable cell surface receptors is impaired but not abolished (reviewed in refs. 29-32) (Figure 5). A recessive IFNGR1 missense mutation (I87T) has been found in one family (13) and dominant small deletions (818del4 or 818delT) in 12 unrelated families (17). The receptors encoded by the I87T allele are detected on the surface of monocytes (13) and probably bind to IFN- $\gamma$ with lower affinity than the normal receptors (the mutation is in the segment encoding the extracellular domain of the receptor). The mutant alleles $818 d e l 4$ and $818 d e l T$ encode truncated, IFN- $\gamma$-binding receptors that accumulate at the cell surface and do not transduce signals, thereby exerting a dominant-negative effect (17). Normal (13) or larger than normal (17) numbers of receptors are detected at the cell surface. The functional defect is only partial, because high concentrations of IFN- $\gamma$ trigger cellular responses. In the patients reported herein and in patients with partial (dominant and recessive) IFN $\gamma R 1$ deficiency, cell surface IFN $\gamma \mathrm{R} 1$ molecules are detectable. However, there 


\section{Figure 4}

Lack of signaling through IFN- $\gamma$ receptors in the cells of the patients. (a) Cultured EBV-B cells from the patients studied (I.1, II.1, III.1), a healthy control individual (positive control, $\mathrm{C}+$ ), a patient reported elsewhere with dominant partial IFN $\gamma \mathrm{R} 1$ deficiency (wt/818del4) (partial deficiency, Pd), and a patient reported elsewhere with complete IFN $\gamma R$ 1 deficiency and no expression of IFN $\gamma R$ 1 (negative control, C-), were stimulated with various concentrations of IFN- $\gamma$ $(\mathrm{IU} / \mathrm{mL})$. Nuclear translocation of STAT-1 was detected by electrophoretic mobility shift assay using a radiolabeled DNA probe. Competition with unlabeled probe (E) is indicated. (b) Cultured SV40-transformed fibroblasts from one patient studied (III.1), a healthy control individual (positive control, $\mathrm{C}+$ ), and a patient reported elsewhere with complete IFN $\gamma R$ 1 deficiency and no expression of IFN $\gamma$ R 1 $($ 107ins4/200+1G $\rightarrow$ A) (negative control, C-), were stimulated with IFN- $\gamma\left(5 \times 10^{4} \mathrm{IU} / \mathrm{mL}\right)$. Cell surface expression of HLA-DR molecules was detected by flow cytometry with an HLA-DR-specific mouse $\mathrm{mAb}$ (dark line) and an isotypic control antibody (light line).

was a complete lack of cellular response to IFN- $\gamma$ only in the four patients studied herein. These results provide further evidence that the IFNGR1 genotype correlates with the cellular, histological, and clinical phenotype (Figure 5). Mutations causing complete IFN $\gamma R 1$ deficiency (irrespective of the presence of surface receptors) are associated with lepromatous-like BCG granulomas and a very severe clinical outcome, contrasting with the tuberculoid granulomas and much better prognosis associated with mild mutations and partial IFN $\gamma R 1$ deficiency.

What is the molecular mechanism underlying the loss of IFN- $\boldsymbol{\gamma}$-binding capacity? Patient III. 1 is a compound heterozygote, and it is therefore unclear whether nonfunctional surface receptors are encoded by $V 61 Q$, or $652 d e l 3$, or both alleles. Patients I.1 and II.1/2 are homozygous for the 295 del12 and C77Y alleles, respectively. The two alleles therefore produce surface receptors that do not bind IFN- $\gamma$. The mutations

\section{Figure 5}

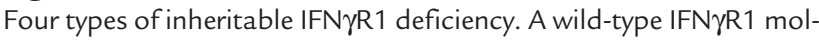
ecule is represented (left), with its extracellular (EC), transmembrane (TM), and intracellular (IC) domains. The horizontal bars in the intracellular region represent the JAK-1- and STAT-1-binding motifs and the receptor recycling motif (17). Four types of mutant IFN $\gamma$ R 1 molecules are represented (right; see text for more details). The first (from left to right) mutant receptor (e.g., that encoded by the IFNGR1 allele 818del4) lacks most of the intracellular domain; the second (e.g., mutant I87T) probably binds IFN- $\gamma$ with a reduced affinity; the third (e.g., mutant C77Y) does not bind IFN- $\gamma$ at all; the fourth (e.g., mutant 107ins4) is not expressed at the cell surface because of a stop codon upstream from the TM domain. The mutations therefore define four types of IFN $\gamma R 1$ deficiency that differ in terms of inheritance (autosomal dominant, AD; autosomal recessive, AR), IFN $\gamma$ R1 cell surface expression (+++, hyperexpression; +, normal expression; -, lack of expression), ${ }^{125}$ I-IFN- $\gamma$ binding to the cells (+, normal; +/-, reduced but not abolished; -, abolished), and/or IFN- $\gamma$-signaling defect (partial, impaired but not abrogated cellular responses to IFN$\gamma$; complete, abrogated cellular responses to IFN- $\gamma$ ).

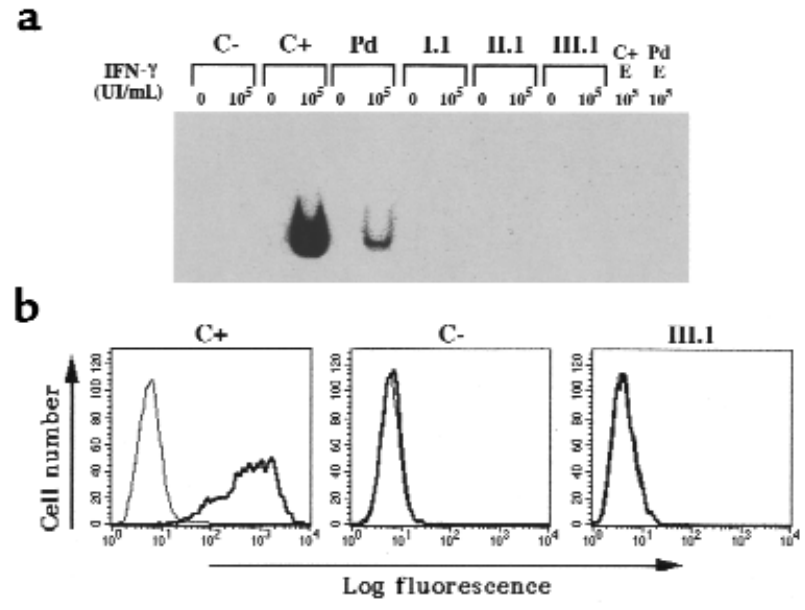

(C77Y, 295del12) affect amino acid residues (63 and 85-88, respectively) in the first domain (encompassing residues 17-105) of the extracellular region of the mature IFN $\gamma$ R1 protein (28) (Table 1). A previous study in which the binding of chimeric mouse and human IFN $\gamma$ R1 molecules to human IFN- $\gamma$ was tested (33), showed the first domain and, to a lesser extent, the second domain, to participate in IFN- $\gamma$-binding. Crystallographic studies determined the three-dimensional coordinates of an IFN $\gamma$ R1-IFN- $\gamma$ complex (28). More accurate resolution of an IFN $\gamma$ R1-IFN- $\gamma$ complex may be obtained in the near future $(28,34,35)$. Mutation C77Y does not alter known contact points between the cytokine and its receptor. The substitution of Cys 63, however, breaks a disulfide bridge with Cys 71, required to maintain the IFN- $\gamma$-binding site intact, as shown previously by site-directed mutagenesis of Cys $63 \rightarrow$ Ser, which abolished binding to IFN$\gamma(36)$. Mutation 295 del12 alters at least one known

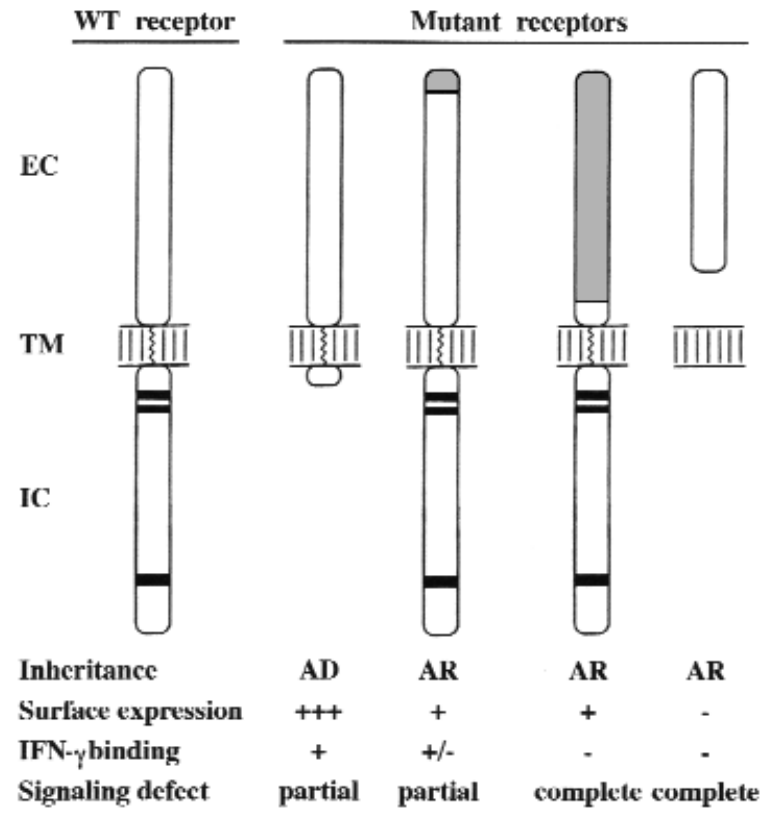


contact point between IFN $\gamma \mathrm{R} 1$ and IFN- $\gamma$. Crystallography showed that $\operatorname{Trp} 85$ in IFN $\gamma \mathrm{R} 1$ forms a hydrogen bond with Gly 18 in IFN- $\gamma$ (28). This probably explains why the deletion of a stretch of four amino acids including $\operatorname{Trp} 85$ (deletion 295del12) greatly reduces the affinity between the two moieties. Overall, the observed effect of the two mutations is consistent with the available structural data.

Why do the IFN $\gamma$ R1-specific mAb's have different recognition patterns for the mutant receptors 295 del12 and C77Y? Mutant 295del12 was recognized on EBV-B cells by all eight specific antibodies tested, whereas mutant $\mathrm{C} 77 \mathrm{Y}$ was recognized only by the 177.1 antibody. On monocytes, however, mutant C77Y was recognized normally by three antibodies $(\gamma \mathrm{R} 99, \mathrm{~A} 6,177.1)$. The epitopes recognized by A6 and $\gamma \mathrm{R} 38$ have been mapped to the first domain, whereas that recognized by $\gamma \mathrm{R} 99$ maps to the second domain (37). The epitopes recognized by the other mAb's (GIR94, GIR208, 21/31.1, 177.1, and IR $\gamma 2$ ) have not yet been mapped. The epitope recognized by $\mathrm{A} 6$ has been investigated extensively in recent years by sitedirected mutagenesis and crystallography (37-42). A6 recognizes a conformational epitope stabilized by Cys 63 (38). The C77Y mutant is recognized on monocytes but not on EBV-B cells by A6, suggesting that Cys 63 and the Cys 63-71 disulfide bridge are important but not essential in the folding of the A6 epitope. A short segment (residues 14-111) in the first domain is well recognized by A6 (39), and several residues, including Trp 85, have been found to be critical for A6 binding (41). However, the 295 del12 mutant (lacking residues $85-88$ ) was detected by $A 6$, suggesting that the lack of residue 85 was compensated for by the loss of the three neighboring residues. The epitope recognized by $\gamma \mathrm{R} 38$ was found to overlap that recognized by A6, accounting for their similar recognition of the mutant 295 del12 $(19,36,38,39,41,42)$. Interestingly, the $\mathrm{C} 77 \mathrm{Y}$ mutant was not recognized by $\gamma \mathrm{R} 38$, even on monocytes, suggesting that Cys 63 and the Cys 63-71 disulfide bridge are essential for the folding of the $\gamma \mathrm{R} 38$ epitope. The epitope recognized by $\gamma \mathrm{R} 99$ has been mapped to the interdomain region and second domain $(19,36,38,41,43)$. This probably explains why 295 del12 and $\mathrm{C} 77 \mathrm{Y}$ receptors, altering residues in the first domain, are recognized by $\gamma \mathrm{R} 99$. Our studies further suggest that residues 85-88 (deletion 295 del12) are not essential for interaction with the five other antibodies tested, whereas Cys 63 (C77Y) is essential for recognition by one other antibody (GIR94) and important for recognition by three other antibodies (21/31.1, GIR208, and IR 2 ). Nevertheless, Cys 63 is not essential for recognition by the $177.1 \mathrm{mAb}$.

Clinically, previous reports have suggested that complete IFN $\gamma$ R1 deficiency can be diagnosed or excluded by flow cytometry with IFN $\gamma \mathrm{R} 1$-specific antibodies $(3-8,11)$. The mutations characterized herein demonstrate that the detection of IFN $\gamma \mathrm{R} 1$ molecules at the cell surface is not sufficient to exclude a diagnosis of complete IFN $\gamma \mathrm{R} 1$ deficiency (Figure 5). Even the normal detection of surface IFN $\gamma$ R 1 with one or more of the seven blocking antibodies tested, as seen with our four patients, does not exclude mutations in the IFN- $\gamma$-binding site causing complete IFN $\gamma$ R1 deficiency. Moreover, the cells from one patient were recognized by all $\mathrm{mAb}$ 's tested, showing that subtle mutations may disrupt the IFN$\gamma$-binding site without altering as many as eight epitopes, including epitopes that probably overlap with the cytokine-binding site of the receptor.

Previous studies have suggested that missense mutations are associated with partial, as opposed to complete, IFN $\gamma$ R1 deficiency (13). Our study demonstrates that the identification of a recessive missense mutation or an in-frame deletion in IFNGR1 is insufficient to exclude complete deficiency. Functional assays should be performed, such as quantification of TNF $\alpha$ production by freshly prepared blood cells stimulated with IFN- $\gamma(5,12)$, detection of STAT- 1 phosphorylation in stimulated freshly prepared monocytes (43), detection of STAT-1 nuclear translocation in stimulated EBV-B cells $(13,17)$, or detection of HLA-DR induction on the surface of stimulated SV40-transformed fibroblasts $(11,13,17)$. Cellular responses to low and high concentrations of IFN- $\gamma$ should be tested to differentiate complete and partial IFN $\gamma \mathrm{R} 1$ deficiency. Accurate molecular diagnosis by biochemical, functional, and genetic studies is of the utmost importance for predicting clinical outcome and guiding the treatment of patients. Partial and complete IFN $\gamma$ R1 deficiency differ markedly in prognosis and treatment. IFN- $\gamma$ treatment may be offered to patients with partial IFN $\gamma$ R1 deficiency, whereas bone marrow transplantation is the only curative treatment available for patients with complete IFN $\gamma R 1$ deficiency. This study stresses the importance of accurate molecular diagnosis of the underlying inherited disorder for the rational treatment of patients with mycobacterial disease.

\section{Acknowledgments}

J.-L. Casanova would like to thank Alain Fischer (Hôpital Necker, Paris, France, EU) for continuing encouragement and support. We thank Françoise Le Deist (Hôpital Necker, Paris, France, EU), Daved H. Fremont (Washington University, Saint Louis, Missouri, USA), and Robert D. Schreiber (Washington University) for helpful discussions. We thank John A. Robinson (University of Zürich, Zürich, Switzerland) for the A6 mAb, Daniela Novick and Menahem Rubinstein (Weizmann Institute of Science, Rehovot, Israel) for the 177.1 antibody, Dieter Moosmayer (University of Stuttgart, Germany, EU) for the IR $\gamma 2$ antibody, and Sidney Pestka (University of New Jersey, Piscataway, New Jersey, USA) for the $\gamma \mathrm{R} 38$ and $\gamma \mathrm{R} 99$ antibodies. This work was supported by grants from INSERM, AFM, PHRC, Legs Poix, and PNRFMMIP. E. Jouanguy was supported by the Ligue Nationale contre le Cancer, S. Dupuis by the MENRT, R. Döffinger by the INSERM and FRM, C. Fieschi by the 
ARC, S. Lamhamedi by the Association Recherche et Partage, and F. Altare by the AFM and INSERM.

1. McKusick, V.A. 1998. Mendelian inheritance in man: a catalog of human genes and genetic disorders. 12th edition. The Johns Hopkins University Press. Baltimore, Maryland, USA. 1930 pp.

2. Casanova, J.L., Newport, M., Fischer, A., and Levin, M. 1999. Inherited interferon gamma receptor deficiency. In Primary immunodeficiency diseases. H.D. Ochs, C.I.E. Smith, and J.M. Puck, editors. Oxford University Press. New York, New York, USA. 209-221.

3. Jouanguy, E., et al. 1996. Interferon-gamma-receptor deficiency in an infant with fatal bacille Calmette-Guerin infection. N. Engl.J. Med. 335:1956-1961.

4. Vesterhus, P., Holland, S.M., Abrahamsen, T.G., and Bjerknes, R. 1998 Familial disseminated infection due to atypical mycobacteria with childhood onset. Clin. Infect. Dis. 27:822-825.

5. Holland, S.A., et al. 1998. Abnormal regulation of interferon gamma, interleukin 12 , and tumor necrosis factor alpha in interferon gamma receptor 1 deficiency. J. Infect. Dis. 178:1095-1104.

6. Roesler, J., et al. 1999. Recurrent mycobacterial and Listeria infections in a child with interferon $\gamma$ receptor deficiency: mutational analysis and evaluation of therapeutic options. Exp. Hematol. 27:1368-1374.

7. Newport, M.J., et al. 1996. A mutation in the interferon-gamma-receptor gene and susceptibility to mycobacterial infection. N. Engl. J. Med. 335:1941-1949.

8. Pierre-Audigier, C., et al. 1997. Fatal disseminated Mycobacterium smegmatis infection in a child with inherited interferon gamma receptor deficiency. Clin. Infect. Dis. 24:982-984.

9. Jouanguy, E., Altare, F., Lamhamedi-Cherradi, S., and Casanova, J.L. 1997. Infections in IFNGR-1-deficient children. J. Interferon Cytokine Res. 17:583-587.

10. Dorman, S.E., et al. 1999. Viral infections in interferon- $\gamma$ receptor deficiency. J. Pediatr. 135:640-643.

11. Altare, F., et al. 1998. A causative relationship between mutant IFNgR1 alleles and impaired cellular response to IFN $\gamma$ in a compound heterozygous child. Am. J. Hum. Genet. 62:723-726.

12. Levin, M., et al. 1995. Familial disseminated atypical mycobacterial infection in childhood: a human mycobacterial susceptibility gene? Lancet. 345:79-83.

13. Jouanguy, E., et al. 1997. Partial interferon-gamma receptor 1 deficiency in a child with tuberculoid bacillus Calmette-Guerin infection and a sibling with clinical tuberculosis. J. Clin. Invest. 100:2658-2664.

14. Emile, J.F., et al. 1997. Correlation of granuloma structure with clinical outcome defines two types of idiopathic disseminated BCG infection. J. Pathol. 181:25-30

15. Casanova, J.L., Jouanguy, E., Lamhamedi, S., Blanche, S., and Fischer, A. 1995. Immunological conditions of children with BCG disseminated infection. Lancet. 346:581.

16. 1997. Primary immunodeficiency diseases. Report of a WHO Scientific Group. Clin. Exp. Immunol. 109(Suppl. 1):1-28.

17. Jouanguy, E., et al. 1999. A human IFNGR1 small deletion hotspot associated with dominant susceptibility to mycobacterial infection. Nat. Genet. 21:370-378

18. Sheehan, K.C.F., Calderon, J., and Schreiber, R.D. 1988. Generation and characterization of monoclonal antibodies specific for the human IFN $\gamma$ receptor. J. Immunol. 140:4231-4237.

19. Garotta, G., et al. 1990. Human interferon- $\gamma$ receptor. Mapping of epitopes recognized by neutralizing antibodies using native and recombinant receptor proteins. J. Biol. Chem. 265:6908-6915.

20. Aguet, M., and Merlin, G. 1987. Purification of human $\gamma$ interferon receptors by sequential affinity chromatography on immobilized monoclonal antireceptor antibodies and human $\gamma$ interferon. J. Exp. Med. 165:988-999.

21. Novick, D., Fischer, D.G., Reiter, Z., Eshhar, Z., and Rubinstein, M. 1989. Monoclonal antibodies to the human interferon-gamma receptor: blocking of the biological activities of interferon-gamma and purification of the receptor. J. Interferon Res. 9:315-328.

22. Watzka, H., Pfizenmaier, K., and Moosmayer, D. 1998. Guided selection of antibody fragments specific for human interferon gamma receptor 1 from a human VH- and VL-gene repertoire. Immunotechnology. 3:279-291.

23. Celada, A., Allen, R., Esparza, I., Gray, P.W., and Schreiber, R.D. 1985. Demonstration and partial characterization of the interferon-gamma receptor on human mononuclear phagocytes. J. Clin. Invest. 76:2196-2205.

24. Greenlund, A.C., Farrar, M.A., Viviano, B.L., and Schreiber, R.D. 1994. Ligand-induced IFN gamma receptor tyrosine phosphorylation couples the receptor to its signal transduction system (p91). EMBOJ. 13:1591-1600.

25. Aguet, M., Dembic, Z., and Merlin, G. 1988. Molecular cloning and expression of the human IFN $\gamma$ receptor. Cell. 55:273-280.

26. Merlin, G., et al. 1997. The gene for the ligand-binding chain of the human IFN $\gamma$ receptor. Immunogenetics. 45:413-421.

27. Beaudet, A.L., and Tsui, L.C. 1993. A suggested nomenclature for designating mutations. Hum. Mutat. 2:245-248.

28. Walter, M.R., et al. 1995. Crystal structure of a complex between interferon- $\gamma$ and its soluble high-affinity receptor. Nature. 376:230-235.

29. Altare, F., et al. 1998. Mendelian susceptibility to mycobacterial infections in man. Curr. Opin. Immunol. 10:413-417.

30. Lamhamedi, S., Jouanguy, E., Altare, F., Roesler, J., and Casanova, J.L. 1998. Interferon gamma receptor deficiency: relationship between genotype, environment, and phenotype. Int. J. Mol. Med. 1:415-418.

31. Ottenhoff, T., Kumararatne, D., and Casanova, J.L. 1998. Novel immunodeficiencies reveal the essential role of type 1 cytokines in immunity to intracellular bacteria. Immunol. Today. 19:491-494.

32. Jouanguy, E., et al. 1999. IL-12 and IFN- $\gamma$ in host defense against mycobacteria and Salmonella in mice and men. Curr. Opin. Immunol. 11:346-351.

33. Axelrod, A., Gibbs, V.C., and Goeddel, D.V. 1994. The interferon- $\gamma$ receptor extracellular domain. Non-identical requirements for ligand binding and signaling. J. Biol. Chem. 269:15533-15539.

34. Chene, C., et al. 1995. Crystallization of the complex of human IFN-gamma and the extracellular domain of the IFN-gamma receptor. Proteins. 23:591-594.

35. Randal, M., and Kossiakoff, A.A. 1998. Crystallization and preliminary xray analysis of a 1:1 complex between a designed monomeric interferongamma and its soluble receptor. Protein Sci. 7:1057-1060.

36. Stuber, D., Friedlein, A., Fountoulakis, M., Lahm, H.W., and Garotta, G. 1993. Alignment of disulfide bonds of the extracellular domain of the interferon gamma receptor and investigation of their role in biological activity. Biochemistry. 32:2423-2430.

37. Bridges, A., et al. 1996. Production and characterization of anti-human interferon gamma receptor antibody fragments that inhibit cytokine binding to the receptor. Protein Eng. 9:365-370.

38. Williams, G., et al. 1995. Dissection of the extracellular human interferon gamma receptor alpha-chain into two immunoglobulin-like domains. Production in an Escherichia coli thioredoxin gene fusion expression system and recognition by neutralizing antibodies. Biochemistry. 34:1787-1797.

39. Ruegg, N., et al. 1995. Mutagenesis of immunoglobulin-like domains from the extracellular human interferon-gamma receptor alpha chain and their recognition by neutralizing antibodies monitored by surface plasmon resonance technology. J. Immunol. Methods. 183:95-101.

40. Bridges, A., et al. 1996. Variable region cDNA sequences and characterization of murine anti-human interferon $\gamma$ receptor monoclonal antibodies that inhibit receptor binding by interferon $\gamma$. Mol. Immunol. 32:1329-1338.

41. Sogabe, S., et al. 1997. Neutralizing epitopes on the extracellular interferon gamma receptor (IFNgammaR) alpha-chain characterized by homolog scanning mutagenesis and $x$-ray crystal structure of the A6 fab-IFNgammaR1-108 complex. J. Mol. Biol. 273:882-897.

42. Hofstadter, K., Stuart, F., Jiang, L., Vrijbloed, J.W., and Robinson, J.A. 1999. On the importance of being aromatic at an antibody-protein antigen interface: mutagenesis of the extracellular interferon gamma receptor and recognition by the neutralizing antibody A6. J. Mol. Biol. 285:805-815.

43. Fleisher, T.A., et al. 1999. Detection of intracellular phosphorylated STAT1 by flow cytometry. Clin. Immunol. 90:425-430. 